\title{
Thyroid disorders in women with abnormal uterine bleeding: a tertiary hospital based cross sectional study from Puducherry, India
}

\author{
Rini Ezhil, Nivedita K.*, Fatima Shanthini N.
}

Department of Obstetrics and Gynecology, Sri Manakula Vinayagar Medical College and Hospital, Puducherry, India

Received: 29 January 2018

Accepted: 06 March 2018

* Correspondence:

Dr. Nivedita K.,

E-mail: niveog91@yahoo.com

Copyright: (C) the author(s), publisher and licensee Medip Academy. This is an open-access article distributed under the terms of the Creative Commons Attribution Non-Commercial License, which permits unrestricted non-commercial use, distribution, and reproduction in any medium, provided the original work is properly cited.

\begin{abstract}
Background: The most common complaint with which women present for gynecological consultation is abnormal uterine bleeding which may be due to varied etiology. Among non-structural causes for AUB, endocrinological disorders like thyroid dysfunction is very common. Thyroid dysfunction is often overlooked, and unnecessary hormonal or surgical interventions are performed in patients with AUB.

Methods: This is a hospital based cross sectional study carried out in Sri Manakula Vinayagar Medical College and Hospital, Puducherry between January 2017 to June 2017 for a period of 6 months and the participants were 200 women attending gynecological OPD with complaints of abnormal uterine bleeding. After obtaining a written informed consent from the participants a detailed history and complete examination including a thorough gynecological examination was performed. A transvaginal ultrasound examination to note for any structural causes for AUB was performed. Thyroid function test (FT3, FT4, TSH) was performed in all study participants and they were then categorized into euthyroid, hypothyroid, hyperthyroid, subclinical hypo or hyperthyroid based on the results. After preliminary preparation all participants were subjected for an endometrial biopsy in the outpatient department and the tissue obtained was sent for histopathological analysis. All the information was tabulated and analyzed using SPSS 22 version with descriptive and inferential statistics (chi square test). A p value of $<0.05$ was considered as statistically significant.

Results: Heavy menstrual bleeding was the most common menstrual abnormality found in $85 \%$ of the study participants.77\% had structural causes for AUB whereas $23 \%$ had non-structural causes. $79.5 \%$ of the patients with AUB were euthyroid whereas $20.5 \%$ had some form of thyroid dysfunction. Subclinical hypothyroidism was the most common thyroid dysfunction $(15.5 \%)$ in this study followed by hypothyroidism $(3.5 \%)$. Only $1.5 \%$ of patients had hyperthyroidism. In the present study no, significant association was found between any particular thyroid dysfunction and specific menstrual pattern or endometrial pattern in histopathology.

Conclusions: Testing and treating for thyroid disorder would prove to be cost effective in patients with AUB particularly with nonstructural causes as it would avoid many costly interventions done for AUB.
\end{abstract}

Keywords: Abnormal uterine bleeding, Endometrium, Menstrual pattern, Nonstructural causes, Thyroid dysfunction

\section{INTRODUCTION}

The most common complaint with which women present for gynecological consultation is abnormal uterine bleeding which may be due to varied etiology ranging from structural causes like polyp, adenomyosis, leiomyoma and malignancy to non- structural causes like coagulation disorders, ovulatory disorders, endometrial and iatrogenic causes. Among them ovulatory 
dysfunction is secondary to endocrinological disorders like PCOD, hyperprolactinemia and thyroid disorders.

$15-26 \%$ of menstrual disorders are attributed to thyroid dysfunction. ${ }^{1}$ Thyroid hormones exert their effect on the menstrual cycles either directly through ovarian specific thyroid hormone receptors or indirectly through their effect on SHBG, prolactin, GnRH and coagulation factors. ${ }^{2,3}$ Alteration in the production and activity of thyroid hormones can cause menstrual abnormalities with hypothyroidism causing menorrhagia and hyperthyroidism presenting with menorrhagia followed by hypomenorrhea. Hypothyroidism is generally associated with proliferative endometrium which is a consequence of relative oestrogen excess due to infrequent or absent ovulation. Even subclinical hypothyroidism which has a high prevalence as high as $9.5 \%$ in women is associated with mild disturbances in menstrual amount and duration. ${ }^{4,5}$

Thyroid abnormalities are also highly prevalent in patients with PCOD and there is a fourfold increased incidence of autoimmune thyroiditis in patients with PCOD. ${ }^{6}$

It has been general practice to perform thyroid function tests in patients with menstrual irregularities only if there is obvious thyromegaly or if symptoms of thyroid disorders are present but menstrual irregularities may precede hypo or hyperthyroidism. Thyroid dysfunction is often overlooked, and unnecessary hormonal or surgical interventions are performed in patients with AUB. Therefore, the awareness of prevalence of thyroid disorders in our population with complaints of AUB, the common menstrual pattern associated with different thyroid disorders and also the endometrial histopathology findings associated with different thyroid disorders will guide us in the management of abnormal uterine bleeding.

The objective of this study was to study the prevalence of thyroid disorders in patient with AUB and to study the menstrual pattern in patients with thyroid dysfunction. To determine the endometrial histopathology associated with different types of thyroid dysfunction.

\section{METHODS}

This is a hospital based cross sectional study carried out in Sri Manakula Vinayagar Medical College and Hospital, Puducherry which caters to the need of rural population. The study duration was between January 2017 to June 2017 for a period of 6 months and the participants were women attending gynecological OPD with complaints of abnormal uterine bleeding.

\section{Inclusion criteria}

- Women with AUB in the age group between 20-70 years

\section{Exclusion criteria}

- Unmarried women

- Known case of thyroid dysfunction

- Known case of carcinoma of cervix or endometrium.

- H/o child birth within a year.

- H/o abortion within 3months

- H/o using exogenous hormones.

- Patients with IUCD insitu

- Known case of bleeding disorders.

Based on the prevalence of AUB, a sample size of 200 was taken to achieve a confidence interval of $95 \%$ with a $5 \%$ margin of error. This study was performed after obtaining approval from the institutional ethical committee. After obtaining a written informed consent from the participants, detailed history regarding the menstrual pattern, duration and quantity of bleeding during each cycle was noted. History suggestive of thyroid dysfunction was obtained. A complete clinical examination including examination of neck for thyroid swelling and a thorough gynecological examination was performed. Apart from performing investigation like $\mathrm{Hb}$, platelet count, RBS and Pap smear a transvaginal ultrasound examination to note for any structural causes for AUB was performed. Thyroid function test (FT3, FT4, TSH) was performed in all study participants by collecting $5 \mathrm{ml}$ of venous blood. Patients were then categorized into euthyroid, hypothyroid, hyperthyroid, subclinical hypo or hyperthyroidism based on the results of thyroid function test. After preliminary preparation all participants were subjected for an endometrial biopsy and the tissue obtained was sent for histopathological analysis. All the information was tabulated and analyzed using SPSS 22 version with descriptive and inferential statistics (chi square test). A P value of $<0.05$ was considered statistically significant.

\section{RESULTS}

Majority of the study participants presenting with AUB were in the perimenopausal age group (59\%). Heavy menstrual bleeding was the most common menstrual abnormality found in $85 \%$ of the study participants. Clinical thyroid examination was positive only in 4 patients (Table 1).

The most common pathology encountered among the patients with AUB was fibroid (44\%) followed by endometrial hyperplasia (16\%) and adenomyosis $(10.5 \%)$. Non-structural causes of AUB was found in $23 \%$ of the participants (Table 2).

In the present study, $79.5 \%$ of the patients with AUB were euthyroid whereas $20.5 \%$ had some form of thyroid dysfunction. Subclinical hypothyroidism was the most common thyroid dysfunction $(15.5 \%)$ in this study followed by hypothyroidism (3.5\%). Only $1.5 \%$ of patients had hyperthyroidism (Table 3). 
Table 1: Patient characteristics.

\begin{tabular}{|c|c|c|c|}
\hline \multicolumn{2}{|c|}{ Patient characteristics } & No. & $\%$ \\
\hline \multirow{5}{*}{ Age } & 20 to 29 years & 6 & $3.0 \%$ \\
\hline & 30 to 39 years & 40 & $20.0 \%$ \\
\hline & 40 to 49 years & 118 & $59.0 \%$ \\
\hline & 50 to 59 years & 34 & $17.0 \%$ \\
\hline & $>60$ years & 2 & $1.0 \%$ \\
\hline \multirow{6}{*}{ Parity } & 0 & 3 & $1.5 \%$ \\
\hline & 1 & 11 & $5.5 \%$ \\
\hline & 2 & 75 & $37.5 \%$ \\
\hline & 3 & 76 & $38.0 \%$ \\
\hline & 4 & 27 & $13.5 \%$ \\
\hline & $>5$ & 8 & $4.0 \%$ \\
\hline \multirow{9}{*}{$\begin{array}{l}\text { Menstrual } \\
\text { pattern }\end{array}$} & $\begin{array}{l}\text { Heavy menstrual } \\
\text { bleeding }\end{array}$ & 170 & $85.0 \%$ \\
\hline & Oligomenorrhoea & 6 & $3.0 \%$ \\
\hline & Polymenorrhoea & 7 & $3.5 \%$ \\
\hline & Polymenorrhagia & 4 & $2.0 \%$ \\
\hline & Amenorrhoea & 1 & $0.5 \%$ \\
\hline & Hypo menorrhoea & 1 & $0.5 \%$ \\
\hline & Metrorrhagia & 0 & $0.0 \%$ \\
\hline & Acyclical bleeding & 2 & $1.0 \%$ \\
\hline & Postmenopausal bleedin & 9 & $4.5 \%$ \\
\hline \multirow{2}{*}{$\begin{array}{l}\text { Thyroid } \\
\text { examination }\end{array}$} & Normal & 196 & $98.0 \%$ \\
\hline & Abnormal & 4 & $2.0 \%$ \\
\hline
\end{tabular}

Table 2: Distribution of structural and non-structural causes in the study.

\begin{tabular}{|lll|}
\hline Cause of AUB & No. & $\%$ \\
\hline Fibroid & 88 & $44.0 \%$ \\
\hline Adenomyosis & 21 & $10.5 \%$ \\
\hline Endometrial polyp & 11 & $5.5 \%$ \\
\hline Endometrial hyperplasia & 32 & $16.0 \%$ \\
\hline Malignancy & 2 & $1.0 \%$ \\
\hline Non-structural causes & 46 & $23 \%$ \\
\hline
\end{tabular}

Table 3: Prevalence of thyroid disorders in abnormal uterine bleeding.

\begin{tabular}{|lll|}
\hline Thyroid abnormalities & No. & $\%$ \\
\hline Euthyroid & 159 & $79.5 \%$ \\
\hline Hypothyroid & 7 & $3.5 \%$ \\
\hline Subclinical hypothyroid & 31 & $15.5 \%$ \\
\hline Hyperthyroid & 3 & $1.5 \%$ \\
\hline
\end{tabular}

Heavy menstrual bleeding was the most common menstrual disorder among our patients $(85 \%)$. Among 170 patients with HMB, 26 had subclinical hypothyroidism and 7 had overt hypothyroidism and only 3 patients with HMB had hyperthyroidism. In the present study no significant association was found between menstrual pattern and any particular thyroid dysfunction $(\mathrm{p}=1.000)$ (Table 4).

Table 4: Association between various menstrual patterns in patients with thyroid disorders.

\begin{tabular}{|c|c|c|c|c|c|c|c|c|}
\hline \multirow{3}{*}{ Menstrual pattern } & \multicolumn{6}{|c|}{ Thyroid status } & \multirow{2}{*}{\multicolumn{2}{|c|}{ Hyperthyroid }} \\
\hline & \multicolumn{2}{|c|}{ Euthyroid } & \multicolumn{2}{|c|}{ Hypothyroid } & \multicolumn{2}{|c|}{$\begin{array}{l}\text { Subclinical } \\
\text { Hypothyroid }\end{array}$} & & \\
\hline & No. & $\%$ & No. & $\%$ & No. & $\%$ & No. & $\%$ \\
\hline Heavy menstrual bleeding & 134 & $84.3 \%$ & 7 & $100.0 \%$ & 26 & $83.9 \%$ & 3 & $100.0 \%$ \\
\hline Oligomenorrhoea & 4 & $2.5 \%$ & 0 & $0.0 \%$ & 2 & $6.5 \%$ & 0 & $0.0 \%$ \\
\hline Polymenorrhoea & 6 & $3.8 \%$ & 0 & $0.0 \%$ & 1 & $3.2 \%$ & 0 & $0.0 \%$ \\
\hline Polymenorrhagia & 4 & $2.5 \%$ & 0 & $0.0 \%$ & 0 & $0.0 \%$ & 0 & $0.0 \%$ \\
\hline Amenorrhoea & 1 & $0.6 \%$ & 0 & $0.0 \%$ & 0 & $0.0 \%$ & 0 & $0.0 \%$ \\
\hline Hypomenorrhoea & 1 & $0.6 \%$ & 0 & $0.0 \%$ & 0 & $0.0 \%$ & 0 & $0.0 \%$ \\
\hline Metrorrhagia & 0 & $0.0 \%$ & 0 & $0.0 \%$ & 0 & $0.0 \%$ & 0 & $0.0 \%$ \\
\hline Acyclical bleeding & 2 & $1.3 \%$ & 0 & $0.0 \%$ & 0 & $0.0 \%$ & 0 & $0.0 \%$ \\
\hline Postmenopausal bleeding & 7 & $4.4 \%$ & 0 & $0.0 \%$ & 2 & $6.5 \%$ & 0 & $0.0 \%$ \\
\hline
\end{tabular}

In the present study, statistically significant association was not found between pathology causing AUB and thyroid dysfunction $(\mathrm{p}=0.066)$.

Among patients having non- structural causes for AUB 14 out of 46 were found to have subclinical hypothyroidism but was not statistically significant (Table 5).
The histopathological examination of endometrium showed different patterns ranging from a normal proliferative endometrium to adenocarcinoma of endometrium in the 200 patients subjected to endometrial biopsy. In this study statistically, significant association was not found between histopathology of endometrium and any particular thyroid dysfunction $(\mathrm{p}$ value $=0.993$ ) (Table 6). 
Table 5: Association between pathology causing uterine bleeding and thyroid disorders.

\begin{tabular}{|c|c|c|c|c|c|c|c|c|}
\hline \multirow{3}{*}{ Pathology causing AUB } & \multicolumn{8}{|c|}{ Thyroid status } \\
\hline & \multicolumn{2}{|c|}{ Euthyroid } & \multicolumn{2}{|c|}{ Hypothyroid } & \multicolumn{2}{|c|}{$\begin{array}{l}\text { Subclinical } \\
\text { hypothyroid }\end{array}$} & \multicolumn{2}{|c|}{ Hyperthyroid } \\
\hline & & $\%$ & No. & $\%$ & No. & $\%$ & No. & $\%$ \\
\hline Fibroid & 78 & $49.1 \%$ & 3 & $42.9 \%$ & 6 & $19.4 \%$ & 1 & $33.3 \%$ \\
\hline Adenomyosis & 17 & $10.7 \%$ & 1 & $14.3 \%$ & 2 & $6.5 \%$ & 1 & $33.3 \%$ \\
\hline Endometrial Polyp & 7 & $4.4 \%$ & 1 & $14.3 \%$ & 3 & $9.7 \%$ & 0 & $0.0 \%$ \\
\hline Endometrial Hyperplasia & 24 & $15.1 \%$ & 2 & $28.6 \%$ & 6 & $19.4 \%$ & 0 & $0.0 \%$ \\
\hline Malignancy & 2 & $1.25 \%$ & 0 & $0.0 \%$ & 0 & $0.0 \%$ & 0 & $0.0 \%$ \\
\hline Non-structural causes & 31 & $19.49 \%$ & 0 & $0.0 \%$ & 14 & $45.1 \%$ & 1 & $33.3 \%$ \\
\hline
\end{tabular}

Table 6: Association between endometrial patterns in patients with thyroid disorders.

\begin{tabular}{|c|c|c|c|c|c|c|c|c|}
\hline \multirow{3}{*}{ Endometrial Histopathology } & \multicolumn{8}{|c|}{ Thyroid status } \\
\hline & \multicolumn{2}{|c|}{ Euthyroid } & \multicolumn{2}{|c|}{ Hypothyroid } & \multicolumn{2}{|c|}{ Subclinical hypothyroid } & \multicolumn{2}{|c|}{ Hyperthyroid } \\
\hline & No. & $\%$ & No. & $\%$ & No. & $\%$ & No. & $\%$ \\
\hline Adenocarcinoma endometrium & 2 & $1.3 \%$ & 0 & $0.0 \%$ & 0 & $0.0 \%$ & 0 & $0.0 \%$ \\
\hline Atrophic endometrium & 2 & $1.3 \%$ & 0 & $0.0 \%$ & 1 & $3.2 \%$ & 0 & $0.0 \%$ \\
\hline Chronic endometritis & 2 & $1.3 \%$ & 0 & $0.0 \%$ & 0 & $0.0 \%$ & 0 & $0.0 \%$ \\
\hline Complex hyperplasia with atypia & 1 & $0.6 \%$ & 0 & $0.0 \%$ & 0 & $0.0 \%$ & 0 & $0.0 \%$ \\
\hline $\begin{array}{l}\text { Complex hyperplasia without } \\
\text { atypia }\end{array}$ & 2 & $1.3 \%$ & 0 & $0.0 \%$ & 1 & $3.2 \%$ & 0 & $0.0 \%$ \\
\hline Proliferative endometrium & 13 & $8.2 \%$ & 0 & $0.0 \%$ & 1 & $3.2 \%$ & 1 & $33.3 \%$ \\
\hline Secretory endometrium & 48 & $30.2 \%$ & 3 & $42.9 \%$ & 11 & $35.5 \%$ & 0 & $0.0 \%$ \\
\hline Shedding endometrium & 32 & $20.1 \%$ & 1 & $14.3 \%$ & 4 & $12.9 \%$ & 1 & $33.3 \%$ \\
\hline Simple hyperplasia with atypia & 1 & $0.6 \%$ & 0 & $0.0 \%$ & 0 & $0.0 \%$ & 0 & $0.0 \%$ \\
\hline Simple hyperplasia without atypia & 56 & $35.2 \%$ & 3 & $42.9 \%$ & 13 & $42 \%$ & 1 & $33.3 \%$ \\
\hline
\end{tabular}

Simple hyperplasia without atypia was the most common endometrial pattern seen in our study (73.1\%). Among 7 patients with overt hypothyroidism 3 had simple hyperplasia without atypia whereas among 31 patients with subclinical hypothyroidism 13 had simple hyperplasia without atypia which is an evidence of chronic anovulation.

\section{DISCUSSION}

The incidence of thyroid disorders in women in Puducherry was $15.8 \%$ of which $11.5 \%$ were hypothyroid and $9.5 \%$ had subclinical hypothyroidism. In our study, which specifically studied women with AUB showed an incidence of $20.5 \%$ compared to $44 \%$ in a study from Delhi by Ajmani et al. ${ }^{7}$ A high prevalence of thyroid disorders was also found by Abdul Hamid et al in their study of thyroid disorder among patients with AUB. ${ }^{8}$

The most common abnormality in our study was subclinical hypothyroidism (15.5\%). Khatiwada et al found that the prevalence of thyroid disorders in women with AUB to be $25.8 \%$ and the most common abnormality to be subclinical hypothyroidism. ${ }^{9}$ Deshmukh et al who studied the association of thyroid disorders with AUB quoted an incidence of $30 \%$ and the commonest abnormality was subclinical hypothyroidism (18\%) followed by overt hypothyroidism (9\%) which is consistent with our study. ${ }^{10}$

Heavy menstrual bleeding was the most common menstrual pattern encountered in our patients with AUB. Majority of the patients with subclinical hypothyroidism (26 out of 31) and overt hypothyroidism (all 7) presented with HMB. Deshmukh et al reported a statistically significant association between menorrhagia and hypothyroidism. ${ }^{10} 53.5 \%$ of hypothyroid women had menorrhagia and $58.6 \%$ of hyperthyroid women had oligomenorrhoea in a study by Javed Ali et al. ${ }^{11}$

Fibroid uterus was the most common pathology found in our patients with AUB and the study did not reveal any significant association between the thyroid status and the pathology causing AUB. 46 (23\%) of our patients had nonstructural causes for AUB among which 14 had subclinical hypothyroidism. A study by Bhavani et al found that there was an association between thyroid disorders and nonstructural causes for AUB which accounted for $76.3 \%$ when compared to $23.6 \%$ of structural causes. ${ }^{12}$ They also found that among nonstructural causes of AUB, subclinical hypothyroidism 
was the commonest $(15.38 \%)$ followed by overt hypothyroidism $(14.2 \%){ }^{12}$

Present study did not reveal any significant association between thyroid dysfunction and endometrial pattern. Verma et al found that $74.3 \%$ of patients with hypothyroidisim had proliferative endometrium. ${ }^{13}$ Padmaleela et al found in their study that the common finding in endometrial biopsy both in hypothyroid (60\%) and hyperthyroid $(57.1 \%)$ cases was proliferative endometrium. ${ }^{14}$ Cystoglandular hyperplasia was found in $13.3 \%$ of hypothyroid patients. ${ }^{14}$ This is evidence to hypothyroidisim casing anovulation and thereby unopposed estrogen action on the endometrium leading to hyperplastic changes in endometrium.

Ajmani et al found that proliferative endometrium was most common endometrium in hypothyroid and in hyperthyroid women most of them had atrophic endometrium. ${ }^{7}$ A high prevalence of anti TPO antibody was found by this author in patients with menstrual disorders as compared to controls. ${ }^{7}$ A high prevalence of thyroid disorders was also found in patients with PCOD thereby emphasizing early testing and treatment of thyroid dysfunction in young patients with PCOS. ${ }^{15}$

\section{CONCLUSION}

The prevalence of thyroid disorders is as high as $15.8 \%$ among woman in Puducherry. So, in woman presenting with AUB, thyroid function test should be mandatory even in the absence of clinical symptoms and signs of thyroid dysfunction. Testing and treating for thyroid disorder would prove to be cost effective in patients with AUB particularly with non-structural causes as it would avoid many costly interventions done for AUB.

\section{Funding: No funding sources}

Conflict of interest: None declared

Ethical approval: The study was approved by the Institutional Ethics Committee

\section{REFERENCES}

1. Morana B, Zarbo R, Puglisi F, Zarbo G Dysfunctional uterine bleeding medical therapies Minerra Ginecol. 2003;55(3):241-51.

2. Doufas AG, Mastorakas G. The hypothalamicpituitary thyroid axis and the female reproductive system. Ann N Y Acad Sci. 2000;900:65-76.

3. Poppe K, Velkeniers B, Glinoer D. Thyroid disease and female reproduction. Clin Endocrinol. 2007;66(3):309-21.

4. Sharma N, Sharma A. Thyroid profile in menstrual disorders. JK Science. 2012;14(1):14-7.
5. Abiraham R, Murugan VS, Pukazhvendan P. Thyroid disorders in women of Puducherry. Indian $\mathrm{J}$ Clin Biochem. 2009;24(1):52-9.

6. Janssen OE, Mehlmauer N, Hahn S, Offner AH, Garmer R. High prevalence of autoimmune thyroiditis in patients with polcystic ovary syndrome. Eur J Endocrinol. 2004;150:363-9.

7. Ajmani NS, Sarbhai V, Yadhav N, Paul M, Ahmad A, Ajmani AK. Role of thyroid dysfunction in patients with menstrual disorder in tertiary care center of walled city of Delhi. J Obstet Gynaecol India. 2016;66(2):115-9.

8. Hamid AMSA, Borg TF, Madkour WAI. Prevalence of hyperprolactemia and thyroid disorders among patients with abnormal uterine bleeding. Int $\mathbf{J}$ Gynecol Obstet. 2015;131(3):273-6.

9. Khatiwada S, Gautam S, Singh S, Shrestha S, Jha P, Baral N, et al. Pattern of thyroid dysfunction in women with menstrual disorders. Ann Clin Chem Lab Med. 2016;2(1):3-6.

10. Deshmukh PY, Boricha BG, Pandey A. The asscociation of thyroid disorders with abnormal uterine bleeding. Int $\mathrm{J}$ Reprod Contracept Obstet Gynaecol. 2015;4:701-8.

11. Javed ali, Karuna Kant Das, Konyak P. Study of relation of thyroid profile with abnormal uterine bleeding. Sch J App Med Sci. 2015:3(7D):2688-92.

12. Bhavani N, Sathineedi A, Chippa S, Reddy VSP. A study of correlation between abnormal uterine bleeding and thyroid dysfunctions. Int $\mathbf{J}$ Recent Trends Sci Tech. 2015;14(1):131-5.

13. Verma SK, Pal A, Jaswal S. A study of thyroid dysfunction in dysfunctional uterine bleeding. Int $\mathbf{J}$ Reprod Conctracept Obstet Gynecol. 2017;6:2035-9.

14. Padmaleela K, Thomas V, Lavanya KM, Kiranmai D. Thyroid disorders in dysfunctional uterine bleeding among reproductive age group women: a cross sectional study in a tertiary hospital in Andhra Pradesh, India. Int J Med pham Sci. 2013;04(01):416.

15. Sinha U, Sinharay K, Saha S, Longkumer TA, Baul SN, Pal SK. Thyroid disorders in polycystic ovarian syndrome subjects. A tertiary hospital based cross sectional study from Eastern India. Indian J Endocr Metab. 2013;17:304-9.

Cite this article as: Ezhil R, Nivedita K, Shanthini FN. Thyroid disorders in women with abnormal uterine bleeding: a tertiary hospital based cross sectional study from Puducherry, India. Int J Reprod Contracept Obstet Gynecol 2018;7:1532-6. 